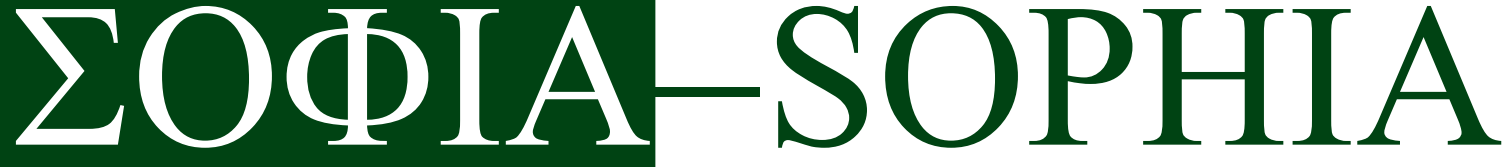

DOI: http://dx.doi.org/10.18634/sophiaj.15v.1i.907

\section{Aprendizaje de dos conceptos semióticos para el análisis cinematográfico}

Learning of two semiotic concepts for movies' analysis

\section{Aprendizagem dos conceitos semióticos para à análise cinematográfica}

María Fernanda Fernández Villa* Angie Tatiana Gutiérrez Ospina**

Diego Arias Cortés*** Castellana de la Universidad del Quindío. Quindío, Armenia, Colombia. maria.ffv22@gmail.com

**Estudiante de la Licenciatura en Literatura y Lengua Castellana de la Universidad del Quindío. Quindío, Armenia, Colombia. angietatiana28@outlook.es

***Docente investigador de la Universidad del Quindío, Master Universitario en Estudios Hispánicos. Quindío, Armenia,

Colombia. ennadaismo@gmail.com

\section{(c) (1) ()}




\title{
Resumen
}

La semiótica es la ciencia que estudia los sistemas de comunicación en el seno social, y lo hace por medio del análisis de las propiedades de los sistemas de signos como base para la comprensión de toda actividad humana. En ese sentido, el objetivo de este texto es presentar un análisis semiótico del cortometraje El más fuerte, que pertenece a la película Relatos salvajes, del año 2014. Para ello se emplean dos conceptos: ocularización y auricularización, con los cuales el cinerrador a través de la elección de planos, ángulos, musicalización, tiempo, entre otros, narra una historia. Para alcanzar este propósito, recurrimos a la propuesta de Gaudreault y Jost (1995) y a la de Paz (2001). Para ellos, el cine permite nuevas formas de oír, ver, sentir y pensar, pues se requiere de múltiples modos para la elaboración de su sentido. En cuanto a los hallazgos, destaca el uso marcado de la ocularizazción y de la auricularización cero en este producto cinematográfico. Además, se concluye con una pequeña reflexión en torno a la posibilidad de llevar estos ejercicios analíticos a las aulas de básica secundaria.

Palabras clave: Semiología, educación, pedagogía, cine, cortometraje.

\begin{abstract}
Semiotics is the science that studies communication systems within human societies by analyzing the general properties of sign systems as a basis for the understanding of all human activity. The objective of this text is to present a semiotic analysis of a short movie, El más fuerte (the strongest one), from the movie Wild Tales (2014), using two concepts: ocularization and auditive representation, with which the movie narrator, through the choice of planes, angles, music and time, among others, tells a story. To achieve this, we use two great exponents of film semiotics: Jost, Metz and Paz Gago, who throughout their lives have made different contributions to semiotic studies of cinema. For them, cinema allows new ways of hearing, seeing, feeling and thinking, because it requires multiple ways for the elaboration of its meaning. By way of conclusion, it can be affirmed that the mentioned concepts, if taken to secondary school classrooms, may enable students to recognize how extra-linguistic aspects influence the intention of discourses and the construction of their meaning.
\end{abstract}

Key words: semiology, education, pedagogy, cinema, short film

\section{Resumo}

A semiótica é a ciência que estuda os sistemas de comunicação dentro das sociedades humanas analisando as propriedades gerais dos sistemas de signos como base para a compreensão de toda atividade humana. $\mathrm{O}$ objetivo deste texto é apresentar uma análise semiótica do curta-metragem "El más fuerte" do filme "Relatos Salvajes" do ano 2014 utilizando dois conceitos: ocularização e auricularização com os quais o narrador do filme através da escolha de planos, ângulos, musicalização, tempo entre outros, conta uma história. Para isso, utilizamos dois grandes expoentes da semiótica cinematográfica: Jost, Metz e Paz Gago, que ao longo de suas vidas fizeram diferentes contribuições para os estudos semióticos do cinema. Para eles, o cinema permite novas formas de ouvir, ver, sentir e pensar, dado que requer múltiplas formas para elaborar seu significado. Como conclusão, pode-se afirmar que os conceitos mencionados, levados às salas de aula do ensino médio, podem capacitar os alunos a reconhecer como os aspectos extralinguísticos influenciam a intenção dos discursos e a construção de seus significados.

Palavras-chave: semiologia, educação, pedagogia, cinema, curta metragem. 


\section{Introducción}

El cine es un medio al que la mayoría de personas tiene acceso, por ende surge el interés de realizar un análisis que permita descubrir algunos de sus aspectos estéticos, que cumplen una función específica y una vez identificada posibilita conocer su intención comunicativa. La semiótica del cine ha realizado investigaciones al respecto que permiten visualizar en el cine un narrador alternativo al tradicional, un cinerrador, es decir, la cámara (los ángulos) y la musicalidad como factor extralingüístico que participa de manera activa en el desarrollo de la trama. Lo anterior es identificado en el film "El más fuerte" de la película Relatos salvajes, en el cual el narrador es construido a partir de los recursos estilísticos del director. Szifrón (2014)

Estos conceptos llevados al aula, le brinda una perspectiva más amplia a los estudiantes sobre los factores que influyen en el discurso, así como la forma en que los aspectos extralingüísticos interactúan de manera directa con el contenido para direccionar la intención comunicativa del locutor. De acuerdo a esto, se expone a continuación la forma en que el concepto tradicional de narrador (una voz que narra), ha sido superado por el cinerrador que recoge todos los elementos presentes en el acto comunicativo para construir significado; una vez expuestos los conceptos, se aplican al film "El más fuerte" que es principalmente narrado por el lente, pues los diálogos son muy escasos; y finalmente, se señala la utilidad de esto en el aula para identificar e interpretar los diversos componentes que direccionan los actos comunicativos para su construcción de significado.

\section{La importancia de ver en Volver de Pedro Almodóvar y corazón salvaje de David Lynch}

En este apartado se presentan dos ejemplos de estudios de la semiótica del filme. El primero realizado por Damián Andrei (2009) a la película Corazón Salvaje de David Lynch; el segundo, elaborado por María Inés Mendoza (2013) en el artículo "Los espacios de /ver/ en Volver'.

El trabajo de Andrei (2009) pretende develar las operaciones discursivas que caracterizan la enunciación de un filme y las estrategias usadas para la construcción de significado; para ello se tomó como referencia $L a$ conversación audiovisual de Gianfranco Bettetini (1984). Con base en esta obra Andrei abordó al sujeto narrador a través de la noción de índice comentativo, el cual consiste en identificar los elementos privilegiados en el desarrollo del filme, las marcas de enunciación y los efectos que estas suponen. También se emplearon los conceptos de ocularización, auricularización y focalización, propuestos por Jost y Gaudreault (1995). Con base en ellos se evidencia lo interesante que es ver cómo las imágenes en el cine resultan más importantes que la historia relatada por los personajes; en otras palabras, cómo la imagen por sí misma narra.

De este análisis se concluye que el cinerrador se encuentra presente en el desarrollo del filme, pues los elementos elegidos como recursos estilísticos (ocularización cero) simulan a lo largo de la película que el personaje no es captado por la cámara, dotándola así con una fuerte sensación de realidad.

En cuanto al trabajo de Mendoza (2013), se plantea identificar el tópico de la muerte a partir de cómo se hace uso de diferentes códigos que otorgan sentido al desarrollo de la historia, esto con base en el concepto de punto de vista (focalización) que se puede atribuir al enunciador. En consecuencia, se reconoce el filme como texto, con la peculiaridad de combinar la banda de la imagen (imágenes fotográficas móviles y secuenciadas de determinada forma) con la banda sonora, que es la mezcla de sonidos (música, diálogos, monólogos).

A partir del análisis de estas dimensiones fílmicas, se puede dar cuenta de cómo el estilo del autor domina la construcción y el modo elegido para el desarrollo del relato.

Se concluye en este documento que identificar estos aspectos permite revelar que en el caso del discurso fílme con el cinerrador solo se puede reconstruir a partir del encuadre elegido:

\footnotetext{
El ángulo de toma remite a ese sujeto de hacer que llamamos enunciador y, al mismo tiempo, la perspectiva así elegida es evidentemente función de ese otro actante que es el enunciatario; pero ninguno de esos dos actantes es directamente identificable en el desarrollo de la película (Courtés, cit. por Mendoza, 2013: 85).
}

Es decir, el enunciador manipula al enunciatario para que adhiera al discurso por el hacer interpretativo que este ejerce.

\section{Significación a partir del uso de las herramientas fílmicas}

Como se puede observar en los dos antecedentes referidos, nociones como cinerrador, ocularización y auricularización son fundamentales para comprender 
cómo se elabora el sentido en el cine. Por tal motivo, a continuación, se definen estos conceptos y, acto seguido, se aplicarán al análisis del cortometraje El más fuerte.

En primer lugar, el cinerrador sugiere una "voz" que cuenta, que conduce la historia dentro del filme; sin embargo, no puede ser solo una voz dado el diverso material del que se componen las películas. Para Paz Gago (2001: 376), el cinerrador implica: "Contar algo por medio de imágenes filmadas, secuenciadas y montadas de determinada forma". Esta categoría dialoga y es adaptada de propuestas de análisis literarios en los cuales se valoran las múltiples formas de narrar al interior de las ficciones escritas. $Y$ dado que la narración escrita y la audiovisual se componen de materia prima distinta, es inobjetable que la manera de narrar en el cine tendrá sus particularidades y recursos propios.

Esta perspectiva en torno al cine se aparta de los estudios de la semiótica tradicional, pues se reconoce la inutilidad de comparar al cine con la lengua como sistema (vieja costumbre semiótica); a propósito afirma Paz Gago (2001: 373): "Contrario de las lenguas, los planos y las secuencias cinematográficas no se prestan a ninguna sistematización paradigmática ni sintagmática".

En segundo lugar, en cuanto a la ocularización, esta noción indica que el texto fílmico es la unión de sistemas de signos indexicales, icónicos y simbólicos (verbales, visuales o auditivos) que permiten el desarrollo de códigos específicos cuyo propósito es cargar la imagen de movimiento, dotándola así de fuerte capacidad narrativa. La ocularización es el foco visual o punto de vista visual que presenta el film y que influye en el desarrollo de la historia (ver Jost y Gaudreault, 1995: 140). En ella se encuentra:

Ocularización interna primaria: Es como el personaje ve (si está ebrio, drogado, es tuerto, etc.). Es seguir su mirada sin tener que mostrarla; quien ve está ausente de la imagen.

Ocularización interna secundaria: Consiste en la subjetividad de la imagen construida por lo raccords, por ejemplo, el plano contra plano. Se muestra el contexto del escenario donde van a suceder los hechos.

Ocularización cero: Es el plano que remite un gran imaginador. Se muestra la escena intentando que se olvide la presencia de la cámara; la posición o el movimiento de la cámara puede subrayar la autonomía del narrador en relación a los personajes; la posición de la cámara puede remitir más allá de su papel narrativo, una elección estilística. De acuerdo con estas posibilidades de la ocularización, se infiere que esta implica el modo en que los elementos visuales se ejecutan en el filme, esto es, la elección de planos y secuencias que genera conexiones con el relato y la posición del espectador. ( González, 2012)

Por último, la auricularización indica un punto de vista sonoro mediante el uso que se hace de los ruidos, música, el habla, etc. El sonido se relaciona con la imagen en pantalla. "El sonido fílmico flota en el espacio de proyección" (Odín, cit. por Gaudreault y Jost 1995: 145). En algunos casos oímos sin ver el origen del sonido. En cuanto a la auricularización, Jost y Gaudreault (1995: 146-147) proponen la siguiente tripartición:

\footnotetext{
Auricularización interna secundaria: La restricción de lo oído a lo escuchado está construida por la representación visual, las señales visuales permiten construir un punto de vista auricular.

Auricularización interna primaria: Un sonido remite a una instancia no visible, sólo cuando ciertas deformaciones del sonido construyan una escucha particular es el indicio de un cambio en el nivel narrativo.

Auricularización cero: Es cuando el sonido del film, como la intensidad de la banda sonora de una de las escenas, es sometido a variaciones según la distancia de los personajes o cuando la música se omite para dar espacio a los diálogos y se remite al narrador implícito.
}

La manera cómo sonido e imagen son manipulados en el cine determinan los diferentes puntos de vista (sonoro y visual) y a su vez definen al cinerrador. $Y$ es a través de estos recursos, de sus modulaciones, como los sentidos y las expectativas del espectador son captados $\mathrm{y}$ afectados mientras ve.

\section{El comportamiento animal bajo el lente de Damián Szifron en Relatos Salvajes}

Relatos salvajes es un filme argentino dirigido por Damián Szifrón en 2014, compuesto por seis relatos titulados: Pasternak, Las ratas, El más fuerte, Bombita, La propuesta y Hasta que la muerte nos separe; todos ellos intensos y con un particular y exquisito humor negro que refleja el comportamiento animal para defensa de los sentimientos humanos. En ellos cada personaje es llevado al límite y obligado a reaccionar de manera brutal frente a situaciones que agreden su dignidad y su ser emocional. Finalmente, en la película se evidencia cómo las reacciones extremas que suceden en el transcurso de cada historia, va 
produciendo gracia en quien la ve, al exhibir la muerte, la violencia, la venganza, en otras palabras, el caos como tal, desenvolviéndose de manera natural que pone a prueba la capacidad del hombre para defenderse, para sobrevivir.

Relatos salvajes fue nominada en la categoría de Mejor película extranjera en los Premios Óscar de 2015 y a 52 premios más, entre ellos Mejor dirección artística en los Premios Sur de 2014, Mejor Película en Premios Forqué de 2015 y Mejor guion original en Círculo de escritores cinematográficos en 2015. Ganó como Mejor película y Mejor director en Premios Sur de 2014, Mejor largometraje Latinoamérica en Premios Forqué de 2015 y Mejor película no inglesa, en Bafta de 2016.

El más fuerte es la lucha entre dos hombres cuyo origen se da por la descortesía de Mario (a todas luces un hombre de clase baja) que le dificulta el paso con su carro a Diego, quien conduce un lujoso Audi y, este último, tras rebasar a Mario después de varios intentos, le hace un fuckyou desde su ventana. Diego continuó tranquilo su camino hasta que la llanta trasera de su auto se pinchó cerca de un puente. Se bajó de su vehículo, miró la llanta y llamó a solicitar ayuda. En la espera de la grúa decidió sacar las herramientas e irlo resolviendo solo. Mientras está en eso observa a lo lejos, tras una nube de polvo, que Mario se acerca en su carro. Diego se asusta y se encierra en su Audi. Mario se parquea frente al auto de Diego y decide tomar revancha del insulto previo. A partir de ese momento empieza una lucha brutal, una cadena de agresiones por parte y parte que, finalmente, desenlaza en la muerte de ambos.

En el desarrollo de este cortometraje los conceptos definidos en el apartado 2 aportan una lectura semiótica en la cual el cinerrador se hace manifiesto en los diferentes tratamientos que el creador del filme aplica sobre el material sonoro y visual de su obra. Dicho tratamiento se ve reflejado en los siguientes fotogramas:

Figura 1. Apertura del filme. (Minuto 21:23).

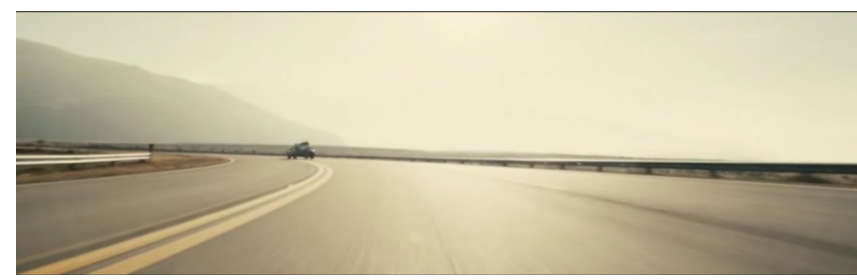

Los fotogramas seleccionados para el análisis conceptual, son extraídos del filme "El más fuerte" que va desde el minuto 20: 34 38: 49, de la película Relatos Salvajes.
En esta imagen se presencia la ocularización cero, pues la vista es propuesta desde la parte inferior delantera del auto de Diego. Se ve una carretera tranquila, un lindo paisaje y un carro más adelante en la curva. El punto de vista no es el de quien conduce, sino de la cámara que pone en contexto al espectador. El fotograma es del inicio del cortometraje. La música que acompaña esta apertura es de Helen St. John: Love the me from flash dance, una canción suave y que comunica tranquilidad, compatible con el lindo paisaje y la vía de la que disfruta Diego al inicio del filme.

Figura 2. Diego rebasa al auto de Mario. (Minuto 22:25).

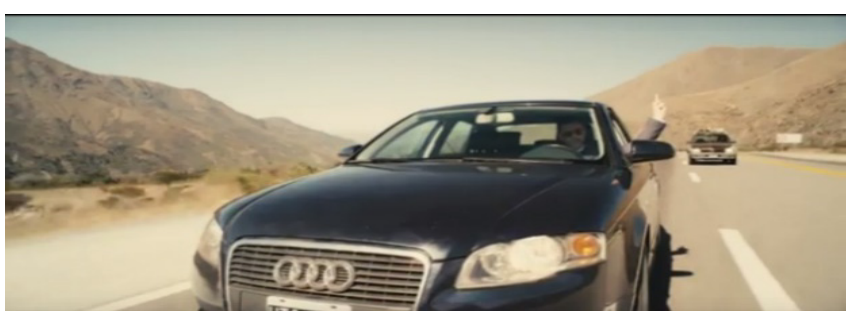

Fuente: relatos salvajes

En la escena de la figura 2 se hace uso de un plano conjunto que nos remite a una ocularización cero, en él se ven los autos como representación del nivel socio-económico de los personajes y un insulto realizado por Diego luego de haber pasado a Mario. Es un punto de vista de la cámara, no es alguien que esté viendo esto al interior de la película. También se hace evidente la auricularización cero, ya que, mientras Diego se aleja de Mario la música inicial retoma la ambientación del filme; es decir, la música remite no a sonidos al interior de la ficción, de los hechos, sino, es una música que viene de afuera.

Figura 3. El neumático pinchado. (Minuto 23:20).

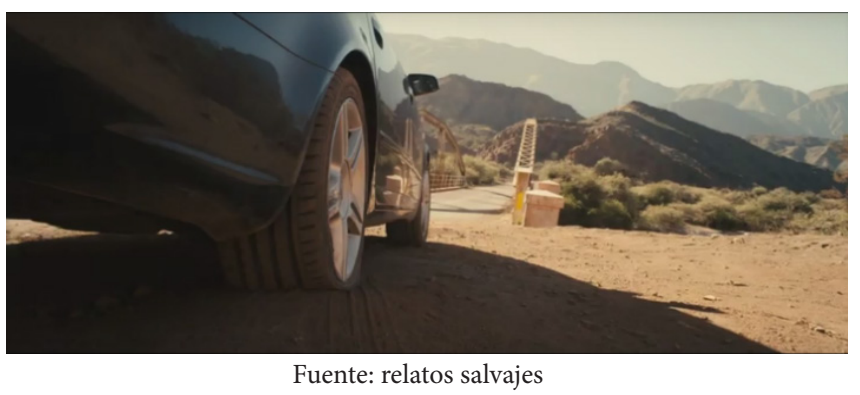

En este fotograma se observa un plano detalle que le permite ver al espectador la llanta pinchada, que al ser el enfoque principal de la toma la convierte en algo representativo para el corto y hace referencia a una 
ocularización cero, en la cual se muestra la autonomía del cinerrador y se puede observar que la llanta trasera del carro de Diego se pincha justo cerca del puente que será más adelante el escenario del desarrollo y desenlace de esta historia. El sonido del auto en movimiento toma protagonismo y se escucha el contacto de este con la arena en el suelo donde Diego decide orillarse. El sonido va disminuyendo hasta que el auto se detiene, lo cual da lugar a una auricularización interna secundaria; esto es, cuando lo oído es construido o producto de la representación visual (se origina al interior de la diégesis).

Figura 4. Diego en el puente. (Minuto 23:33).

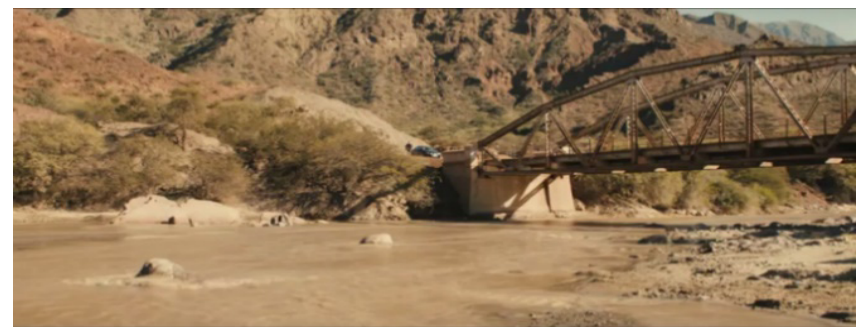

Fuente: relatos salvajes

En el fotograma de la figura 4 se identifica una ocularización cero, gracias al uso de un gran plano general, que permite ver el escenario completo en el cual se encuentra detenido Diego por el inconveniente con su llanta (se ve a Diego junto a su auto en un extremo del puente). Con esta imagen se confirma que: "Un solo plano puede no comunicar nada. En cambio, si lo ponemos en funcionamiento en el contexto del resto de los planos, adquirirá un significado más allá de lo que muestra" (Viarengo, 2001:45) o sea, esta imagen toma mayor importancia a lo largo del filme ya que allí se desarrolla y se desenlaza la historia. Esta ocularización (punto de vista) adquiere mayor relevancia semántica dado que va acompañada de una auricularización cero; en otras palabras, la imagen en movimiento se aúna a un sonido agudo (que genera tensión) ajeno al personaje. La intensidad del sonido asciende mientras la cámara se acerca en zoom a Diego. De repente el sonido es cortado cuando se muestra, en otro plano, a Diego abriendo la puerta del baúl de su Audi.

Figura 5. Piedra al agua. (Minuto 24:44)

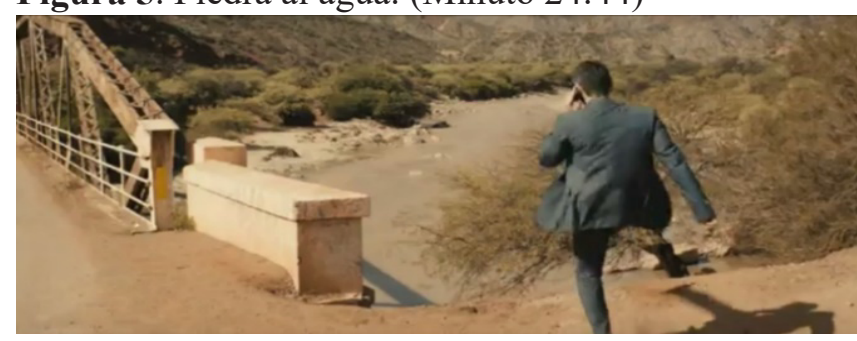

Fuente: relatos salvajes
En la figura 5 un plano entero muestra a Diego pateando molesto una piedrita que va a caer al río. Esto lo hace mientras llama a la grúa para que le colabore con su auto. Acá se refleja una ocularización interna secundaria, pues se ve a Diego de pie frente a la bajada al río y mirando hacia este. Cuando avanza un poco se escucha el sonido del teclado de su celular, sus pasos en la arena, y también se oye patear la piedra, más el sonido de esta al caer en el agua. Lo que sucede entonces, es que la ocularización enunciada se combina con una auricularización interna primaria, es decir, sonidos que se mezclan con la imagen que vemos, pero de los cuales no vemos explícitamente su origen, simplemente los suponemos.

Lo que sucede en los fotogramas de las figuras $4 \mathrm{y}$ 5 demuestra cómo en el cine hay múltiples recursos, distintos de lo literarios, para dar sentido a la historia narrada en imágenes, para capturar la atención del espectador a través de los modos en que imagen y sonidos son tratados por el creador cinematográfico.

Figura 6. Preludio de una desgracia. (Minuto 25:44 26:15)
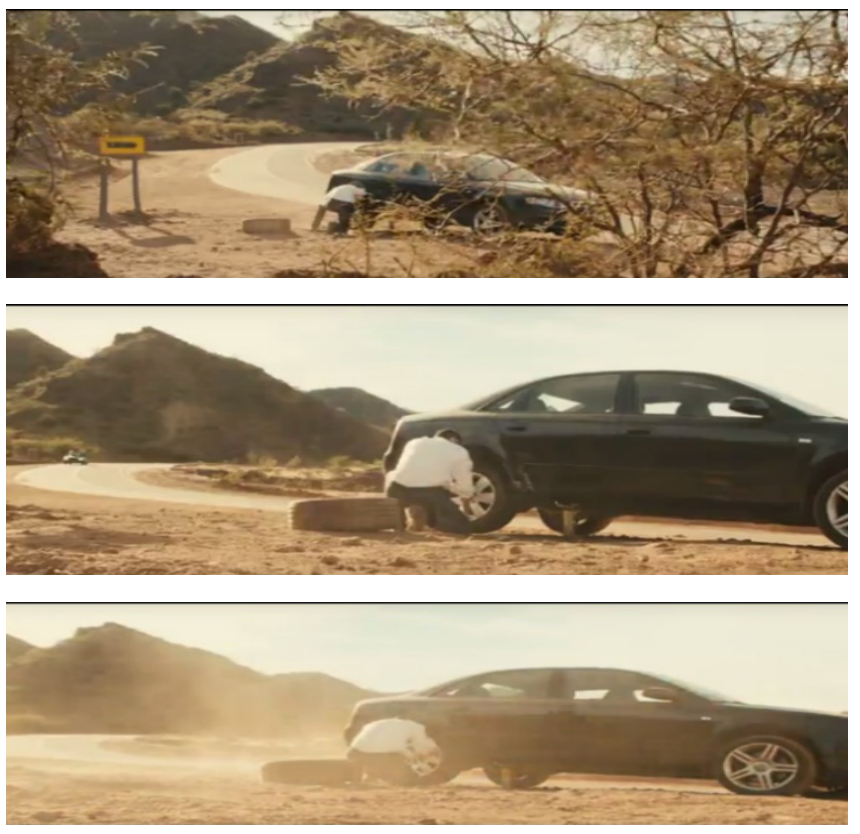

Fuente: relatos salvajes

Es importante ver estas tres escenas juntas porque su secuencia indica un incremento en la tensión narrativa, en la expectativa del espectador; son, además, el anuncio de un giro narrativo. A partir de este momento se inicia una confrontación salvaje entre los dos personajes de esta historia. En los fotogramas presentados se identifica una ocularización cero, pues los ángulos usados muestran a Diego desde una perspectiva ajena, 
como si fuese observado por alguien más y la cámara no estuviese allí presente. No se sabe quién lo ve. En el primer fotograma se muestra a Diego intentando solucionar el problema por sí mismo, pero lo vemos a través de unos arbustos, como si alguien lo espiara. En la siguiente imagen sucede algo bastante significativo: se levanta una nube de polvo. Ya no se ve a Diego a través de los arbustos, sino que se aprecia cómo una nube de polvo se acerca a él y quita visibilidad a la carretera.

Parece que el cinerrador informa que se aproxima la acción. En este fragmento del filme el espectador es consciente de que algo intenso va a suceder pronto, pero Diego no lo sabe. La nube de polvo podría ser un acontecimiento normal dado a las condiciones del sitio (focalización cero); no obstante, estas imágenes van acompañadas de una auricularización interna secundaria, dado que el sonido mezclado con las imágenes procede de la actividad de Diego (intento de cambiar la llanta), del viento y las ramas que éste agita a su paso. Esta mezcla de sonidos e imágenes produce una tensión ascendente que se materializa con la llegada de Mario en su auto y que develan que la nube de polvo era en realidad un anuncio (un acontecimiento simbólico e intencionado creado por el autor del filme).

Cuando Diego ve que Mario se acerca, se refugia en el interior de su auto. Se evidencia que le tiene miedo a Mario. Este se parquea delante del Audi, se baja de su carro y empieza a atacar al auto de Diego. Desde fuera lo reta, destruye las plumillas y golpea el parabrisas. Ante esto, se observa cómo Diego de a poco se va transformando, como el miedo empieza a abandonarlo. La conclusión de las agresiones se materializa cuando Mario orina y defeca sobre al Audi. A partir de ese momento descubrimos a un nuevo Diego, su versión salvaje.

Figura 7. Agresión y transformación. (Minuto 29:45 30:51).

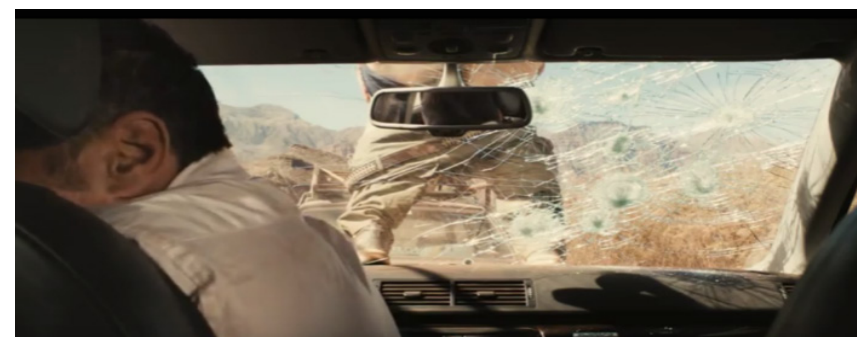

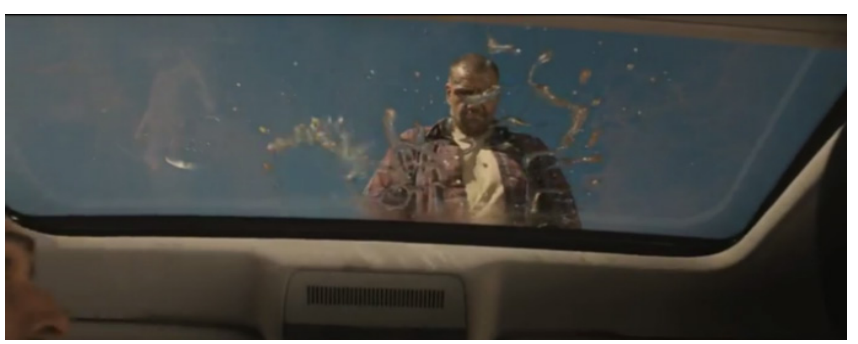
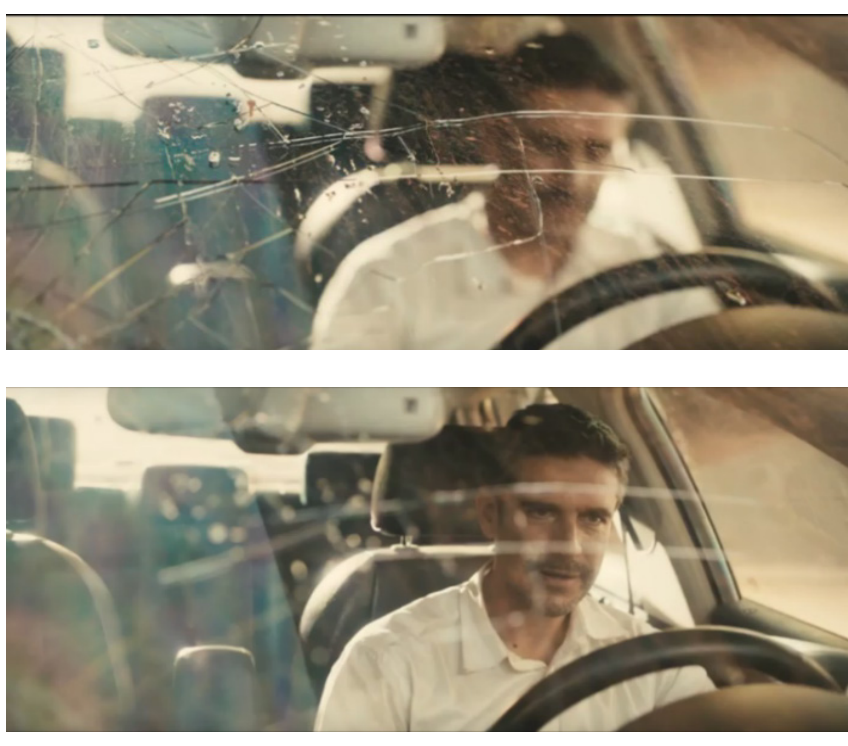

Fuente: relatos salvajes

En los dos primeros fotogramas de la figura 7 se ve el gesto de desagrado de Diego, pues se alcanza a notar su rostro en el espejo retrovisor y en el hecho de voltearse y no ver cómo Mario orina y defeca sobre su auto. Estos dos últimos actos de Mario, más que agredirlo físicamente, lo hieren en su ego, en su dignidad. Los ángulos de las imágenes proponen los hechos desde el punto de vista de Diego. El primero es natural y el segundo en contrapicado. Esta situación, más que las anteriores, desata la lucha de "el más fuerte".

Las siguientes dos imágenes de la figura 7 resaltan (o enfocan) primero, el parabrisas roto y se aprecia a Diego al fondo, difuminado; segundo, se ve a Diego con una actitud de resolución y el parabrisas difuminado. Se nota a este personaje distinto, se escucha su respiración fuerte (auricularización interna secundaria), y se advierte un cambio narrativo en el que se invierten los papeles. Vemos al hombre herido en lo más profundo de su ser; no lo vemos desde el punto de vista de Mario, sino, más bien, desde la perspectiva de quien construye el personaje (ocularización cero). Así, el espectador sabe del cambio efectuado en Diego, pero Mario desconoce dicha transformación (no sabe lo que se le avecina). El parabrisas roto coincide, además, con algo que en la personalidad del conductor del Audi se rompió. 
Figura 8. La batalla final. (Minuto 33:38 - 34:54).
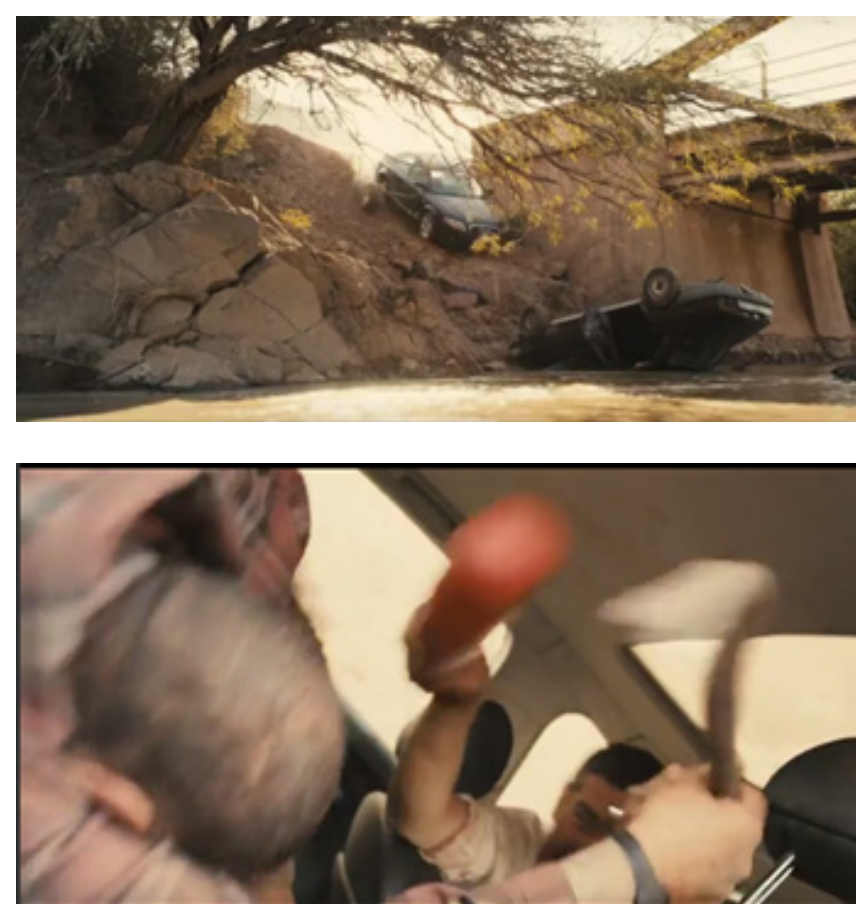

Fuente: relatos salvajes

La figura 8, primer fotograma, es un plano general (ocularización cero) en la que se muestra cómo debido al incidente del neumático, Diego termina cayendo sobre el auto de Mario. En el segundo fotograma se hace uso de un contra plano (ocularización interna secundaria) en el cual, dentro de los vehículos destrozados, los personajes continúan irreversiblemente el enfrentamiento. Se ve cómo Diego, en un plano detalle, toma un extintor como arma para defenderse de Mario. Luego lo golpea con este y se libera su contenido (en la figura 9 se aprecia a Mario envuelto por el gas del extintor). En el desarrollo de la figura 8, primer fotograma, hay una auricularización interna secundaria, en la que los sonidos son la respuesta a lo visto; es decir, a los golpes que ellos se dan. En el siguiente fotograma, hay una auricularización interna primaria, pues en la lucha encienden la radio y suena una música que no se relaciona directamente con lo que sucede, sino que es más bien opuesta a lo que se ve.

Figura 9. Los últimos momentos. (Minuto 35:54).

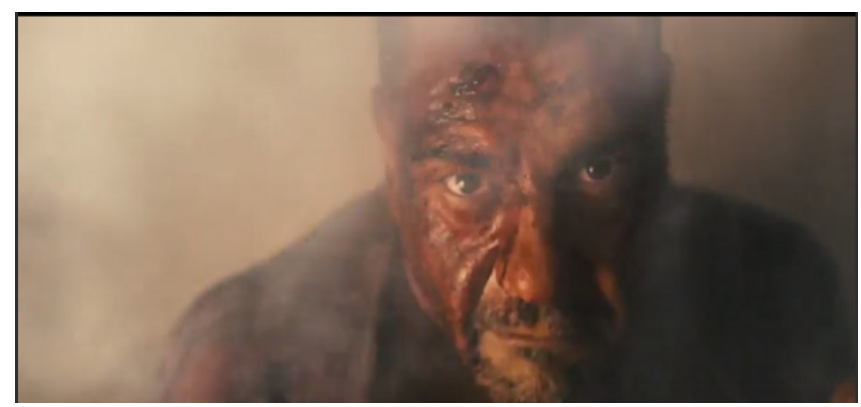

Fuente: relatos salvajes
La figura 9 concuerda con una ocularización interna primaria, pues se hace uso de un primer plano, en el que se visualiza a Mario (desde la mirada de Diego) con una expresión fuerte y decidida; la expresión de este es también alusiva a los sentimientos de los dos: ninguno se va a ir sin destruir por completo al otro. El gas que salió del extintor y el gesto en la cara ensangrentada de Mario son señal que solo uno puede ser "el más fuerte".

Figura 10. Un abrazo para el final. (Minuto 37:17 $38: 47)$.
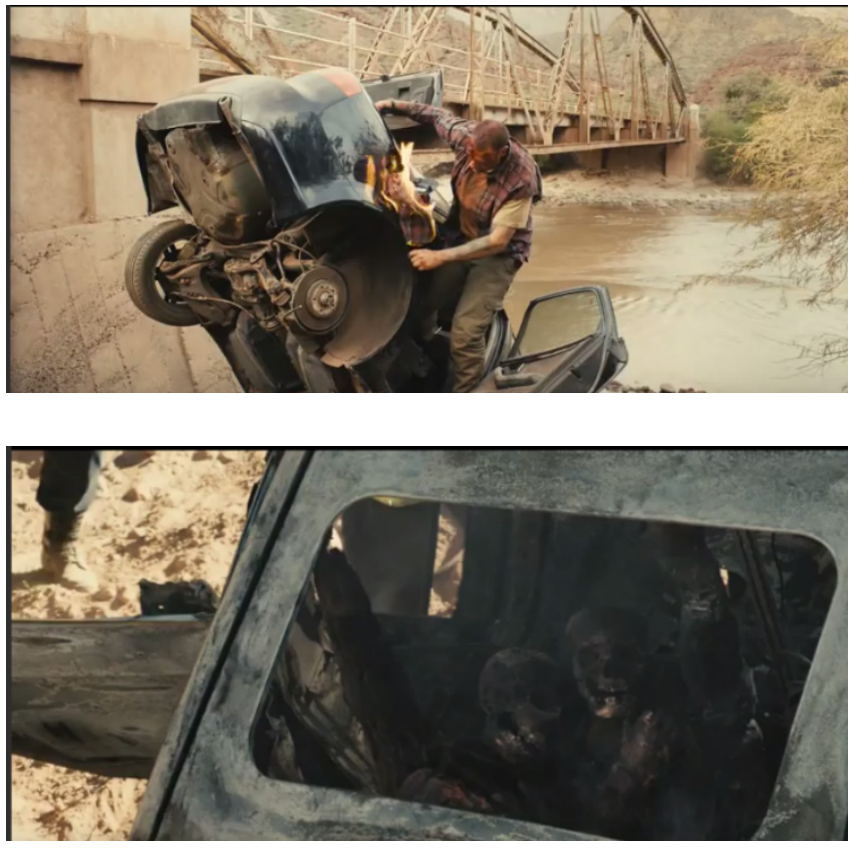

Fuente: relatos salvajes

El plano general del fotograma 1, figura 10, permite ver desde afuera (ocularización cero) el auto de Diego sin su llanta trasera, a Mario prendiendo fuego a un trapo que ha ubicado en el compartimento de la gasolina. Vemos esta escena no desde la mirada de uno de los personajes de la diégesis, sino, por el contrario, desde fuera, como espectadores acomodados o acostumbrados a una forma de mostrar que propone el director. En lugar de ver los hechos desde este plano, pudieron ser presentados en ángulo picado o contrapicado, en un gran plano, en ángulo quebrado, etc.

La última escena, segundo fotograma, es realmente significativa, pues es la parte viva del exquisito humor negro que maneja el director de esta película. La ciega lucha en la que se enfrentaron Diego y Mario los condujo a la muerte. Aquélla empezó en la vía, con una gesticulación obscena y unas palabras fuertes; luego, se trasladó a sus autos, empleados como armas y como trincheras para el refugio. Pero también, en el interior 
de uno de ellos, el Audi de Diego, se desarrolló la batalla final entre estos dos hombres. Allí terminaron juntos, abrazados y carbonizados. Así los vemos gracias a la cámara que se acerca lentamente: dos rescoldos sin expresión alguna abandonados en un abrazo. La cámara los muestra $\mathrm{y}$, mientras tanto, se oyen los diálogos de dos agentes que han acudido a la escena del siniestro; escuchamos sus voces (auricularización interna secundaria) que señalan, absurdamente, que pudo haber sido un crimen pasional. Posteriormente, cuando la cámara se acerca más a las víctimas, se deja de lado la voz de los agentes y emerge un sonido agudo ascendente que ha estado presente a lo largo de la película y que, en numerosas ocasiones, ha contribuido a que el espectador sepa, en parte, qué va a suceder. Finaliza el cortometraje así, con una auricularización cero.

En varias ocasiones en el filme, como en esta última figura, se refleja como la convencionalidad de los signos remite, automáticamente, a una interpretación inconsciente y estereotipada. Los agentes que llegan al sitio toman como hipótesis principal (por estar "abrazados" Mario y Diego) que fue un crimen pasional y no consideran una posible lucha, qué fue lo que aconteció. Algo semejante sucede cuando Mario, antes del desenlace, está enfrentando a Diego y por el lado de estos pasa un camión al que Diego, desde su Audi, le pita desesperadamente en señal de ayuda. Pero Mario, disimulando, levanta su mano hacia el conductor del vehículo en señal de saludo. Un signo de ayuda, el de Diego, y otro de "saludo", el de Mario. Quien conduce y los ve, relaciona esto, el gesto de Mario y el pito del auto de Diego, con un saludo. Acto seguido, él también responde pitando; o sea, corresponde al supuesto saludo.

\section{Conclusión}

De manera sucinta, como se pudo observar en el análisis del filme, el uso de la ocularizacón y auricularización dan como resultado el cinerrador, el cual se construye a partir de la elección y combinación de recursos visuales y auditivos que brindan al espectador un acercamiento más intenso sobre lo que sucede en la historia. Así se dota a la imagen y al movimiento de esta de un significado que dinamiza la narración. El movimiento de la imagen es lo que permite que el narrador ya no sea solamente "una voz que cuenta algo" como lo propuso inicialmente Genette ( citado por Paz Gago, 2001: 376), sino que la historia pueda ser contada por medio de imágenes simples e incluso incluir implícitamente al espectador en el desarrollo de la trama.
Asimismo, en el análisis de las escenas seleccionadas, el corto, en una alta proporción, posee un cinerrador externo a la diégesis (ocularización cero), así se refleja en la mayoría de los fotogramas, otorgando autonomía al narrador. Se evidencia esto en la figura 6, cuando la cámara parece espiar a Diego mientras cambia la llanta y el polvo sube anunciando que se acerca otro vehículo (que instantes después aparece en la imagén). Este fragmento visual se complementa con una auricularización interna secundaria, la cual indica que lo escuchado es construido por lo visto. Así mismo se visualiza en la figura 7 que posee una ocularización cero y señala los actos de Mario que modifican la actitud pacifica inicial de Diego, despertando en él su conducta animal para defender su "orgullo".

La ocularización cero que se marca a lo largo del filme, evidencia la intención del director en este cortometraje (en el que hay pocos diálogos) por construir un cinerrador autónomo, que involucra directamente a quien lo ve. Esto se consigue gracias a la presencia de detalles simbólicos intencionados que, materializados en imágenes en movimiento, anticipan acciones futuras que los personajes desconocen. En el caso de la auricularización, con sus respectivas variaciones (sonidos cuyo origen se rastrean al interior de la diégesis o que provienen fuera de esta),se usa como en la figura 8 para crear efectos humorísticos en el espectador. Por ejemplo, cuando en medio de la lucha se enciende la radio del auto de Diego y suena una canción cuyo tono tranquilo no coincide con el tono salvaje de la pelea que se da entre ellos. En la figura 10 se revela otro efecto humorístico o irónico cuando llega la grúa y al interior de ésta se escucha canción romántica que, por azar, coincide con la explosión que pone final a la lucha entre los dos protagonistas.

Los conceptos anteriormente nombrados trabajan en conjunto, la elección de estos incide directamente en lo que la escena desea mostrar, pues si a una de estas imágenes se le cambiase el plano o la musicalización, su significación se modificaría por completo y el cinerrador plantearía otra intención.

El aprendizaje de estos conceptos de semiótica pueden ser utilizados en otros procesos pedagógicos, puesto que "el concepto del cinerrador hace posible una mayor facilidad para comprender la enunciación que se produce tras la observación del espacio" (Gómez, 1997: 71), por lo tanto es importante identificar los distintos recursos de los que se hace uso en los actos comunitavos y también los modos en que estos se presentan de acuerdo con las apreciaciones que el autor desea que el destinatario 
perciba. Los conceptos mencionados en el presente artículo, llevados a las aulas de básica secundaria, pueden posibilitar a los estudiantes reconocer cómo los aspectos extralingüísticos influyen en la intención de los discursos, en la construcción de su significación, ya que "la maduración intelectual y humana que se pretenden como objetivos finales del Bachillerato, dependen en gran parte del desarrollo en el alumno de su capacidad de comprensión y análisis de los discursos audiovisuales" (Alonso, 2002: 108). Aquí se abordaron desde el cine, pero también sirven como instrumento interpretativo de los discursos literarios (en ellos rastreamos su origen), de los anuncios publicitarios, discursos políticos, y todos aquellos presentes en los massmedia.

\section{Referencias bibliográficas}

Alonso, F. (2002). "El cine como asignatura en el Bachillerato". Tarbiya, Revista de investigación e innovación educativa, (31): 107-113.

Andrei, D. (2009). Análisis semiótico de la película Corazón Salvaje; de David Lynch. Blog dedicado a profesionales en el área de la comunicación. Universidad de Buenos Aires, Argentina.

Bettetini, G. (1984). La conversación audiovisual. Madrid: Cátedra.

Gago Paz, J. (2001). Teorías semióticas y semiótica fílmica. Cuadernos de la Facultad de Humanidades y Ciencias Sociales. Universidad Nacional de Jujuy. 17, 371-387.

Gaudreault,A.y Jost, F. (1995). El relato cinematográfico, Cine y narratología. Barcelona: Ediciones Paidós.

Gómez Padilla, M. (1997). "El espacio, en el café de doña rosa; el cinerrador". En Gómez Blanco, C.J (ed.) Literatura y cine: perspectivas semióticas: actas del I Simposio de la Asociación Galega de Semiótica. disponible en: http://hdl.handle. net/2183/9597

González, I. (2012). Lo que la camara muestra y lo que el personaje ve. El espectador Imaginario, 37, $1-4$.

Mendoza, M. (2013).Los espacios del ver en la película Volver de Pedro Almodóvar. DeSignis, 20, 79-87
Telam (2015) Relatos Salvajes va al Oscar como mejor película extranjera., consultado en http://www. telam.com.ar/notas/201501/91987-relatos-salvajes-nominada-al-oscar-a-mejor-pelicula-extranjera.html

Szifron, D. (2014). Relatos Salvajes. Argentina: Kramer \& Sigmall Film

Viarengo, M. (2001). Algunos elementos de cine. Pulso Audiovisual. 1, 45. 